\title{
Did the Student-Instructor and Peer-to-Peer Divide Widen with Instructional Changes during COVID-19?
}

\author{
Allison K. Murray ${ }^{a^{*}}$, Somesh P. Roy ${ }^{a}$, Madeline Hahn ${ }^{\mathrm{b}}$, Philip A. Voglewede \\ a Department of Mechanical Engineering, Opus College of Mechanical Engineering, \\ Marquette University, Milwaukee WI 53233 USA \\ ${ }^{\mathrm{b}}$ Department of Educational Policy and Leadership, Marquette University, Milwaukee \\ WI 53233 USA \\ * Corresponding author: allison.murray@marquette.edu
}

\begin{abstract}
The rapid shift to online and HyFlex learning due to the COVID-19 pandemic caused an abrupt reconceptualization of higher education and learning communities. It also provided a fertile ground for experimentation and observation about the student experience in a highly fluid learning environment. The work presented herein was a quantitative and qualitative analysis of the student experience grounded in the theory of transactional distance. It explored the divide between students and their peers and instructors. It was hypothesized that the distance students perceived between themselves and their peers, instructors, and content was affected by the modality (in-person, online, or hybrid) in which a course was offered during the Fall 2020 semester. The Revised Scale of Transactional Distance (RSTD) instrument was deployed as a quantitative tool, and it was found that modality was a significant factor in students' perceived transactional distance. In-person classes had the shortest perceived distance between students and their instructors and peers; conversely, online courses resulted in the largest divide. A systematic qualitative analysis identified three themes in student interview data: changes in learning environments, changes in learning strategies, and changes in relationships with professors. The implications of these data were discussed and mitigation strategies including intentionality in course design and collaborative spaces were presented.
\end{abstract}

Keywords: COVID-19; transactional distance; HyFlex instruction; engineering; online courses

\section{Introduction}

The shift to online and hybrid learning of Spring and Fall 2020 due to the COVID-19 pandemic caused unprecedented disruption to student learning and educational communities. Courses were reformatted to conform to online delivery, many of which made the transition without pedagogical intentionality. Students were thrust into fully online work and then transitioned to HyFlex methods of instruction (i.e., in-person, online synchronously, and online asynchronously) (Beatty, 2019; Milman et al., 2020; Maloney and Kim, 2020). Instructors pivoted their teaching methods to account for these HyFlex models and hastily experimented to find the optimal strategy to foster learning while maintaining instructional continuity. Many of these changes, and the associated negative and positive outcomes, will ripple through higher education for 
years. It is of paramount importance to document the effect on student learning and educational communities and move forward with intentional pedagogical choices for the permanently changed higher education landscape. The authors argue that if various facets of this transitionary phase of the instructional delivery are not studied, it will be a missed opportunity to "return to better," in the haste to "return to normal." It is in this spirit the current study was performed to look at students' perception of various course modalities and how students perceived it affected their learning. The authors performed surveys and interviews of the undergraduate student population to collect quantitative and qualitative data on the students' perceptions. We also attempted to learn from this data to better plan for future semesters and an increasingly hybrid environment.

This study leveraged the framework of transactional distance (Moore, 1993, 2018 , etc) to explore the effect of pandemic instructional practices on the student experience. Work herein hypothesized that the student experience was highly correlated to the modality in which their course was offered. The work presented was a mixed methods analysis of the student experience and perceived transactional distance during the Fall 2020 semester at a mid-sized, private, religiously affiliated, R2, Midwestern institution that focuses on the undergraduate experience. The effect of modality, gender, and graduation year on transactional distance were presented. Likewise, student interview themes of changes in learning environments, changes in learning strategies, and changes in relationships with professors were detailed. The implications of these data were extrapolated to the larger focus of the study: an increased understanding of the student experience during online and HyFlex learning during this educational environment transformation, and beyond.

\section{Research Context}

The reconceptualization of learning spaces, including physical and virtual classrooms, caused by social distancing during COVID-19 has already been reported in various sources. Cahapay insisted that the increased transactional distance experienced by students must be addressed to avoid leaving behind traditionally underserved student populations (Cahapay, 2020). While many classrooms during COVID-19 merely tried to repurpose in-person teaching styles in an online platform, additional work suggested that successful online teaching must have pedagogically informed design with a focus on high engagement (Kalantzis and Cope, 2020). Kalantzis and Cope suggested that online learning could be as effective as, or more effective than, in-person teaching but must be designed with the modality in mind (Kalantzis and Cope, 2020). This was further supported by the assertion that instructors must move beyond the emergency remote teaching of Spring 2020 and into an intentional online learning environment moving forward (Adedoyin and Soykan, 2020). Ilagan reported that with appropriate instructional design, a blend of scaffolded assignments, and asynchronous video lectures there was a reduced transactional distance in a computer programming class during the COVID lockdown (Ilagan, 2020).

With specific focus on online learning, Fatani (Fatani, 2020) reported evaluation of online videoconferencing-based instruction using Students' Evaluations of 
Educational Quality (SEEQ) (Marsh, 1992). Yilmaz (Yilmaz and Yilmaz, 2020) used a Motivated Strategies for Learning Questionnaire (MSLQ) (Pintrich et al., 1991) along with an instrument to measure transactional distance to evaluate instructional design practices in the online learning environment.

Beyond the learning outcomes, research on the student experience and the mental load of higher education in this moment has been published. Work presenting the emotional experience of students during a radical shift in their educational environment has been reported (Park et al., 2020). Vielma and Brey analyzed the experience of students in biomedical engineering courses during the Spring of 2020 (Vielma and Brey, 2020). They explained that students self-reported motivational challenges, course content discontinuities, lack of faculty-student interactions, and challenges in peer-to-peer collaboration (Vielma and Brey, 2020).

\section{Theoretical Framework}

The theory of transactional distance, originally proposed by Moore, described the physical and psychological distance that students must overcome in online learning (Moore, 1993; Moore and Kearsley, 2011; Moore, 2018). It was proposed that students require a balance of autonomy, structure, and dialog to thrive in distance education. The balance of these components, or lack thereof, contributed to three perceived "distances", which can be classified as student-to-content, student-to-instructor, and student-tostudent distances. Autonomy was based upon the student having the ability to develop their learning plan, acquire resources independent of the course, and evaluate their own performance. Structure encompassed the flexibility of the course's learning objectives and assessment tools. This component was relevant to how much a student may tailor the course experience to their learning style. Lastly, dialog was the amount of instructor-to-student or peer-to- peer interactions that support the knowledge gain of a student. In general, more structure increased the transactional distance as it reduced the flexibility, whereas more dialogue and increased levels of autonomy decreased the distance.

An instrument to measure the transactional distance experienced by college students in web-based learning modalities was originally proposed by Zhang (Zhang, 2003). This instrument was further refined and validated to the Revised Scale of Transactional Distance (RSTD) (Paul et al., 2015). The RSTD had 12 Likert scale questions that focused on the student-to-student, student-to-instructor, and student-tocontent distances. This measure was used to correlate student engagement and transactional distance in online learning (Bolliger and Halupa, 2018; Yilmaz and Yilmaz, 2020; Doo et al., 2020; Yilmaz and Keser, 2017; Kumtepe et al., 2017). Bolliger and Halupa found that transactional distance was a valid predictor of student engagement at three private, US colleges (Bolliger and Halupa, 2018). Doo et al. used the RSTD to explore the connection between self-regulation and learning engagement in flipped classrooms and found that transactional distance had a mediating effect in the relationship between self-regulation and learning engagement (Doo et al., 2020). 
Yilmaz and Yilmaz used the RSTD framework to evaluate the effectiveness of learning analytics as a metacognitive tool in online classes (Yilmaz and Yilmaz, 2020).

The theory of transactional distance proposed that an intentional course design that balanced structure, autonomy, and dialog would result in the highest student learning outcomes. The rapid changes to online instructional methods during 2020 exposed the need for intentional and planned changes in course design when moving towards online or HyFlex teaching. Several authors have argued that shifts towards online instructional delivery could be expected to continue in the future, even after COVID (Dhawan, 2020; Kalantzis and Cope, 2020; Li and Lalani, 2020; DePietro, 2020; Park et al., 2020).

The authors theorized that the transactional distance survey would not provide the full context of the student experience in such a tumultuous learning environment. As such, the research team deployed targeted interviews and qualitative analysis to provide contextual understanding of the quantitative results.

\section{Research Methods}

The work presented herein sought to measure the transactional distance students were experiencing in their courses during COVID-19 and to identify the effect of course modality (in-person, online, and hybrid) on the students' perceived distance. It should be noted that hybrid was defined in this work colloquially to match the University language as a course simultaneously offered in-person and virtually. It is not defined as blended learning with in-person and virtual complementary content. In this work, the three modes are defined as follows:

- In-person: All lectures are delivered in-person in a physical classroom, socially distanced.

- Online: All lectures are delivered online, either synchronously or asynchronously.

- Hybrid: The instructor delivers all lectures in a physical classroom while also live broadcasting. The students rotate between attending the lecture in-person in the classroom and via online synchronously.

The authors hypothesized that the transactional distance students were experiencing was correlated to the modality in which their course was offered and, in turn, contributed to engagement and motivational challenges students were experiencing. Quantitative analysis of survey data, using the RSTD instrument, captured the three modes of transactional distance: student-to-student, student-to-content, and student-to-instructor. The effect of modality and student demographics on the distance was reported. In addition, qualitative analysis of student interview data has been presented to provide additional context on the increased distance between students and their peers and instructors during COVID-19. 


\section{Participants}

A two-round survey was sent to all enrolled full-time undergraduate engineering students in four departments: biomedical; civil, construction, and environmental; electrical and computer; and mechanical engineering. 159 students responded in the first survey and 58 in the second survey. The optional, self-reported demographic breakdown was presented in Table 1. Nine students - as indicated in Table 1 - were selected, at random, from the survey participants for voluntary interviews.

Table 1: The demographic makeup of student respondents to both rounds of survey delivery and interviews. The demographic data was optional and self-reported. Note that percentages may not add up to $100 \%$ due to students who chose not to report or identified as more than one racial or ethnic group.

\begin{tabular}{lccccccc}
\hline & $\begin{array}{c}\text { Num. of } \\
\text { Response }\end{array}$ & $\begin{array}{c}\% \\
\text { Asian }\end{array}$ & $\begin{array}{c}\% \\
\text { Black }\end{array}$ & $\begin{array}{c}\% \\
\text { Latinx }\end{array}$ & $\begin{array}{c}\% \\
\text { White }\end{array}$ & $\begin{array}{c}\% \\
\text { Female }\end{array}$ & $\begin{array}{c}\% \\
\text { Male }\end{array}$ \\
\hline Survey 1 & 159 & 3.8 & 3.1 & 18.9 & 74.8 & 42.7 & 46.5 \\
\hline Survey 2 & 58 & 8.6 & 0 & 13.8 & 77.6 & 50 & 44.8 \\
\hline Interview & 9 & 0 & 0 & 11 & 89 & 78 & 22 \\
\hline
\end{tabular}

\section{Quantitative Methods}

The instrument in this work was the Revised Scale of Transactional Distance (RSTD) (Paul et al., 2015). This instrument had 12-questions with a 5-point Likert scale, as detailed in Table 2. Students completed the RSTD instrument for each modality (inperson, online, and hybrid) in which their courses were offered. They were instructed to answer with respect to a specific course for each modality. Lower transactional distance corresponded to stronger agreement with the statement except for SI-1 (the instructor pays no attention to me) which was negatively coded. The instrument was delivered twice to all undergraduate engineering students. Students were presented with identical instruments in both rounds. Round 1 of data collection occurred during weeks 7 and 8 of the 14-week semester and Round 2 of data collection occurred one week after final exams.

Data was included in the set if the respondent self-reported as an undergraduate engineering student and completed at least $25 \%$ of the survey content with a complete RSTD response for at least one modality. Survey responses that did not meet these criteria were removed from the data set. A Cronbach Alpha test was completed on both survey rounds to measure internal reliability. Round 1 had a standard alpha of 0.87 . Round 2 had a standard alpha of 0.90. Each question on the instrument was tested for significant difference between Round 1 and 2 using a Mann-Whitney $U$ test with a null hypothesis of $H_{0}: S_{1 k}=S_{2 k}$ where $S_{1 k}$ and $S_{2 k}$ were the population median of responses to the $\mathrm{k}^{\text {th }}$ question in the first and second survey round, respectively. The alternative hypothesis was non-equal medians. There was not a significant difference found in the population median response to any question between survey Round 1 and Round 2 at a significance level of $\alpha=0.05$. 
Three hypotheses were tested in this work: that modality, graduation year, and gender influenced the perceived distance students felt between themselves and peers, instructors, and content. Each hypothesis was tested for each of the 12 RSTD questions, resulting in 36 tests per data collection round. These were tested with a Kruskal-Wallis test with the RSTD response as the ordinal dependent variable. The null hypothesis, alternative hypothesis, and factor type for each independent variable were reported in Table 3.

Table 2: Revised Scale of Transactional Distance (RSTD) question text as adopted from Paul et al. (Paul et al., 2015) and corresponding question identification number. Response options were a 5-point Likert scale from Strongly Disagree to Strongly Agree.

\begin{tabular}{c|c}
\hline \multicolumn{1}{c|}{ Question Text } & Question ID \\
\hline The instructor pays no attention to me. & SI-1 \\
\hline The instructor was helpful to me. & SI-2 \\
\hline $\begin{array}{c}\text { The instructor can be turned to when I need help in the course. } \\
\text { The course emphasized synthesizing and organizing ideas, information, or } \\
\text { experiences into new, more complex interpretations and relationships. }\end{array}$ & SI-4 \\
\hline $\begin{array}{c}\text { This course emphasized making judgments about the value of information, } \\
\text { arguments, or methods such as examining how others gathered and incorporated } \\
\text { data and assessing the soundness of their conclusions. }\end{array}$ & SC-2 \\
\hline $\begin{array}{c}\text { This course emphasized applying theories and concepts to practical problems or } \\
\text { in new situations. }\end{array}$ & SC-3 \\
\hline I get along well with my classmates. & SS-1 \\
\hline I feel valued by the class members in this class. & SS-2 \\
\hline My classmates in this class value my ideas and opinions very highly. & SS-3 \\
\hline Mhe class members are supportive of my ability to make my own decisions. & SS-5 \\
\hline
\end{tabular}

Table 3: The null and alternative hypotheses, independent variable, factor type and test method for the quantitative analysis. $S_{I, j k}, S_{O, j k}, S_{H, j k}$ were the population medians of the in-person, online, and hybrid responses, respectively, for the $k^{\text {th }}$ question in the $j^{\text {th }}$ survey round. $S_{g i, j k}$ was the population median of the $i^{\text {th }}$ graduation year for the $k^{\text {th }}$ question in the $j^{\text {th }}$ survey round. $S_{f, j k}$ and $S_{m, j k}$ were the population median of the female and male respondents, respectively, for the $k^{\text {th }}$ question in the $j^{\text {th }}$ survey round.

\begin{tabular}{ccccc}
\hline Independent Variable & Null Hypothesis & Alternative Hypothesis & Factor Type & Levels \\
\hline Modality & $S_{I, j k}=S_{O, j k}=S_{H, j k}$ & $\begin{array}{c}\text { At least one non-equal } \\
\text { median }\end{array}$ & Nominal & $\begin{array}{c}\text { (3) In-person, } \\
\text { Online, Hybrid }\end{array}$ \\
\hline Graduation Year & $S_{g 1, j k}=\cdots=S_{g n, j k}$ & $\begin{array}{c}\text { At least one non-equal } \\
\text { median }\end{array}$ & Ordinal & (7) 2020-2026 \\
\hline Respondent Gender & $S_{f, j k}=S_{m, j k}$ & $S_{f, j k} \neq S_{m, j k}$ & Nominal & $\begin{array}{c}\text { (3) Female, Male, } \\
\text { Non-Binary }\end{array}$ \\
\hline
\end{tabular}




\section{Qualitative Methods}

Nine students who participated in the first survey were interviewed during weeks 11 and 12 of the Fall 2020 semester. These students were representative of all four engineering disciplines at the institution: biomedical; civil, construction, and environmental; electrical and computer; and mechanical engineering. Students self-identified their race, ethnicity, and gender identity, as reported in Table 1. All interviews were recorded, anonymized, and transcribed for qualitative analysis.

The interview transcripts were analysed thematically, following the procedure detailed by Braun and Clarke (Braun and Clarke, 2006). This process required drawing out "repeated patterns of meaning" (Braun and Clarke, 2006, p.86) across the data set and identifying the emerging themes to generate rich descriptions of the data at both high and more detailed levels. Under this approach, descriptive themes and codes were developed to capture how engineering students describe and discuss their learning experiences during the COVID-19 pandemic.

Individual interview transcripts were first read repeatedly for data immersion and familiarization, and initial ideas regarding possible themes and codes within the transcripts were noted. Based on this, codes were then generated systematically across the data set and collated to fit under emerging themes, such as changes in learning strategies and changes in student-professor relationships. These themes and codes were iteratively reviewed and refined for the generation of clear definitions and for the construction of an overall data story.

\section{Research Findings}

\section{Quantitative Results}

The distribution of responses to each RSTD question for survey Rounds 1 and 2 were presented in Figures 1 and 2, respectively. The percentage of total responses in each respondent group was shown from strongly disagree (left, dark orange) to strongly agree (right, dark teal) in which the width of the color bar indicated the relative response rates. The question ID shown in these figures referenced the full question text in Table 2.

A Kruskal-Wallis test with independent variable modality was performed on each RSTD prompt for both rounds of the survey. The p-value and chi-squared values for those tests were reported in Table 4.

The effect of gender and anticipated graduation year were investigated using a Kruskal-Wallis test with a significance level of $\alpha=0.05$. The data was not disaggregated by modality for this analysis. It was found that gender had a significant effect on student response to SS-3 (my classmates in this class value my ideas and opinions very highly) in Round $1(\mathrm{p}=0.04)$ and SS-5 (the class members are supportive of my ability to make my own decisions) in Round 2 ( $\mathrm{p}=0.03)$. It was found that the reported anticipated graduation year had a significant effect on student responses to SI-4 (the instructor can be turned to when I need help in the course) in Round 1 ( $p=0.03$ ) and 
SS-3 (my classmates in this class value my ideas and opinions very highly) in Round 2 $(\mathrm{p}=0.04)$.

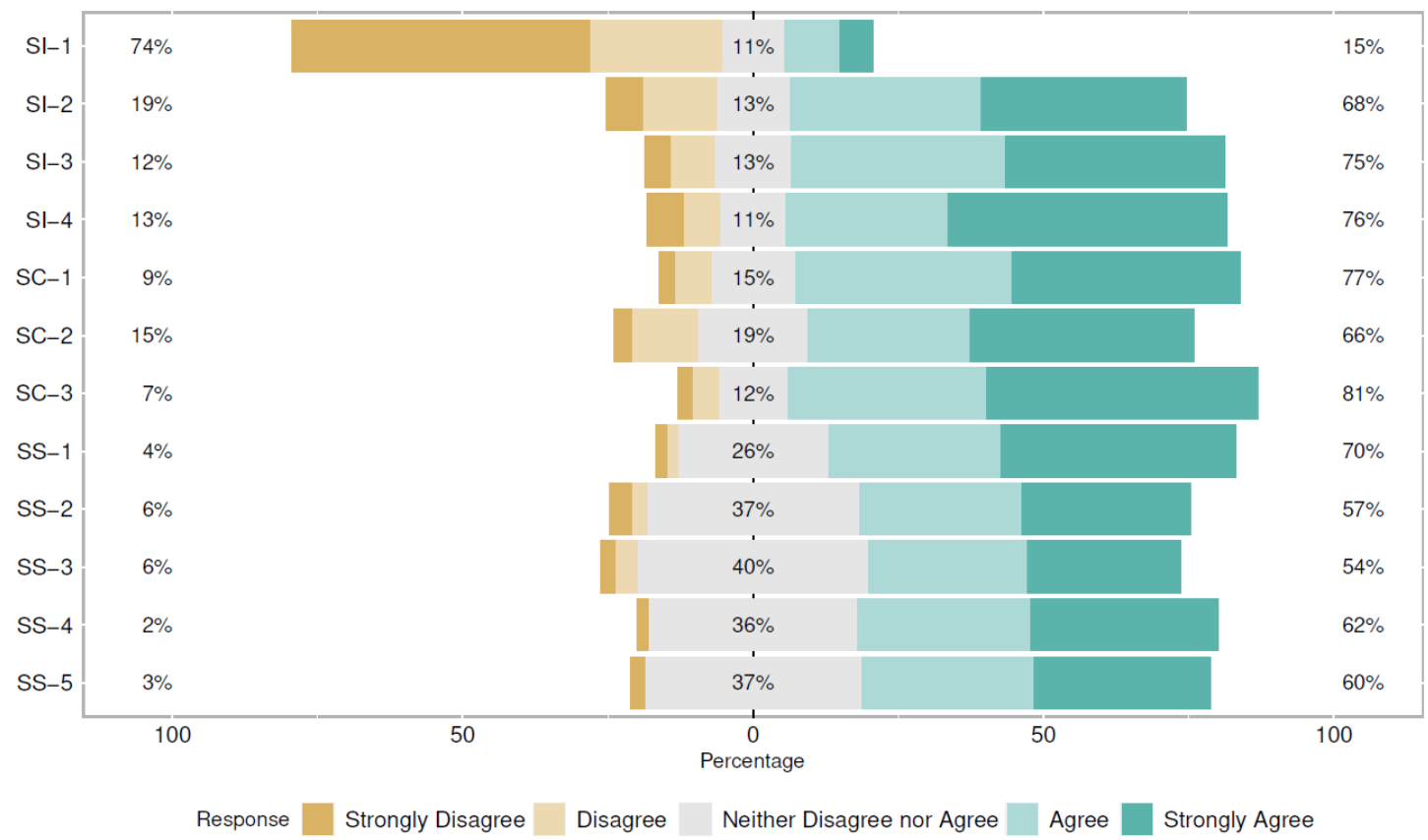

Figure 1: Student responses to each Round 1 RSTD question on a 5-point Likert scale from Strongly Disagree (left, dark orange) to Strongly Agree (right, dark teal) presented as the percentage of total responses for each category. The question ID corresponds to the question text in Table 2.

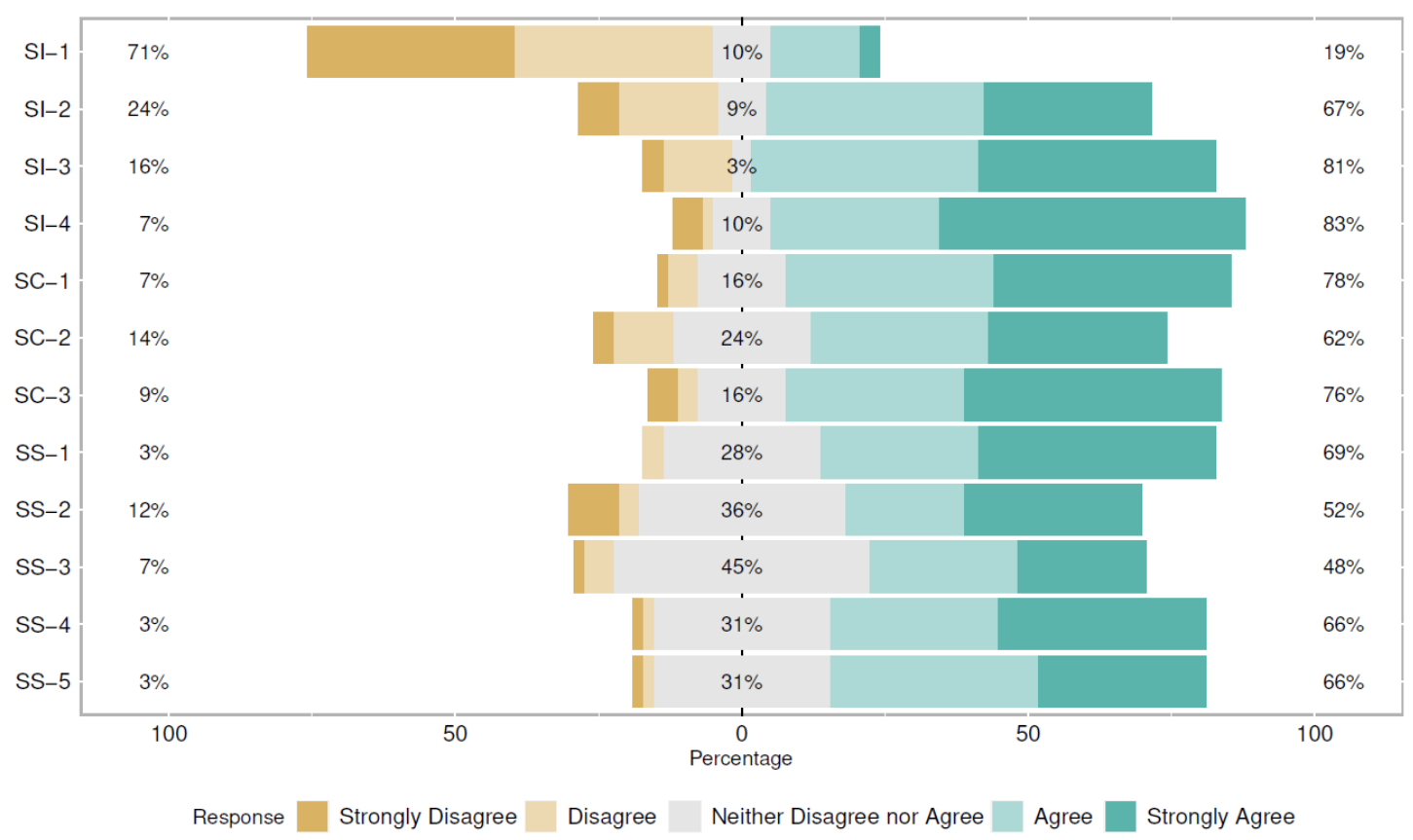

Figure 2: Student responses to each Round 2 RSTD question on a 5-point Likert scale from Strongly Disagree (left, dark orange) to Strongly Agree (right, dark teal) presented as the percentage of total responses for each category. The question ID corresponds to the question text in Table 2. 
Table 4: The p-value and chi-squared value for a Kruskal-Wallis test performed on each RSTD prompt for both survey rounds with modality as the independent variable at a significance level of $\alpha=0.05$. The null hypothesis for each test was $H_{0}: S_{I, j k}=S_{O, j k}=S_{H, j k}$ where $S_{I, j k}, S_{O, j k}, S_{H, j k}$ were the population medians of the in-person, online, and hybrid responses, respectively, for the kth question in the jth survey round. The alternative hypothesis was that at least one median was non-equal. Significant $p$-values are indicated with a*.

\begin{tabular}{ccccc}
\hline Question & \multicolumn{2}{c}{ Round 1 } & \multicolumn{2}{c}{ Round 2 } \\
\cline { 2 - 5 } ID & p-value & $\mathrm{X}^{2}$ & p-value & $\mathrm{X}^{2}$ \\
\hline SI-1 & $0.01 *$ & 16.04 & $0.02 *$ & 8.45 \\
SI-2 & $0.01 *$ & 9.73 & $0.05^{*}$ & 5.95 \\
SI-3 & $0.01 *$ & 12.86 & $0.03 *$ & 6.73 \\
SI-4 & $0.03 *$ & 7.31 & 0.29 & 2.51 \\
\hline SC-1 & $0.02 *$ & 7.5 & 0.16 & 3.68 \\
SC-2 & $0.01 *$ & 10.8 & 0.33 & 2.21 \\
SC-3 & 0.15 & 3.71 & 0.59 & 1.04 \\
\hline SS-1 & 0.11 & 4.49 & 0.19 & 3.29 \\
SS-2 & 0.08 & 5.04 & 0.35 & 2.11 \\
SS-3 & 0.09 & 4.72 & 0.43 & 1.71 \\
SS-4 & $0.03 *$ & 6.94 & 0.14 & 3.99 \\
SS-5 & $0.03 *$ & 7.21 & 0.67 & 0.79 \\
\hline
\end{tabular}

The distribution of responses to each question with a significant modality effect for Round 1 was presented in Figure 3 and broken down by modality. Due to the small sample size $(\mathrm{N}=58)$ in the Round 2 modality data sets, namely the in-person $(\mathrm{N}=9)$ and online $(\mathrm{N}=16)$ course data, the Round 2 data was not broken down by modality. 


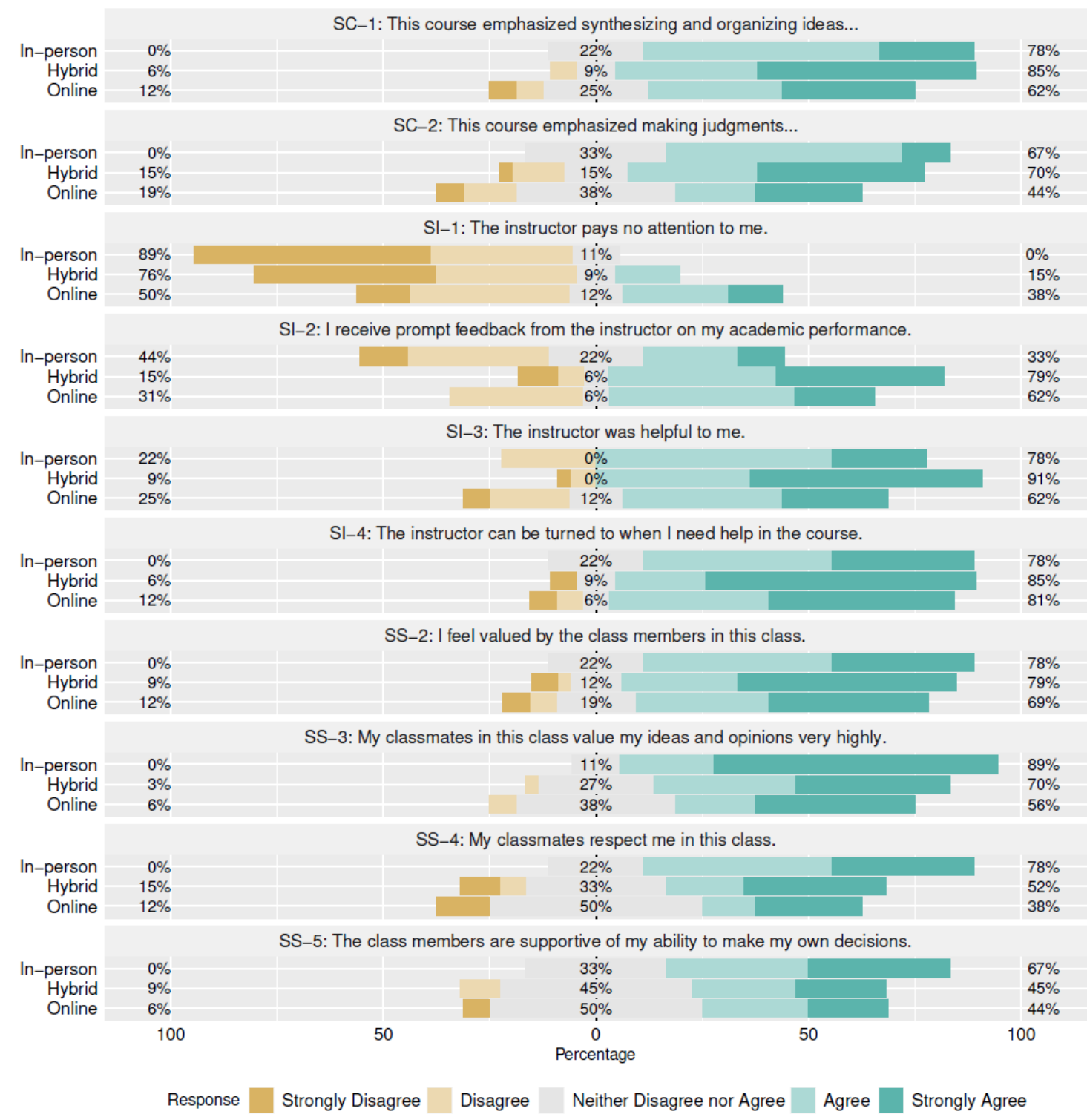

Figure 3 The breakdown of student responses to Round 1 RSTD questions by modality on a 5-point Likert scale from Strongly Disagree (left, dark orange) to Strongly Agree (right, dark teal) presented as the percentage of total responses for each category. Only those questions which had a significant modality effect, using a Kruskal-Wallis test at $\alpha=0.05$, were presented.

\section{Qualitative Results}

Three interview themes were identified: (1) differences in learning experiences based on course modality, (2) changes in learning strategies and study habits, and (3) changes in relationships with professors.

\section{Learning Experience and Course Modality}

The first, and most salient, theme was differences in learning experiences based on course modality. The courses in the Fall 2020 semester were offered as fully online, hybrid, and fully in-person. All interviewees commented on the decreased opportunities for, and impact of, interactions with their peers and/or professors. Students reported 
fewer interactions, especially in online environments than in past semesters. Additionally, students expressed an increased anxiety and decreased effectiveness during face-to-face interactions. In-person classes were considered the most engaging due to a larger perceived level of interaction. A representative student statement on the reduced interaction was:

...if you want to like make a joke in class, you'd normally would whisper it to the person next to you and it'd be good. But you can't really whisper anything to the person next to you because then the whole class and the professor is going to hear you and that's just not going to go well. Or you can't really ask anyone, "Can I borrow a pen?" Because that's problematic or like anything like that, it's just cutting off short interactions that could lead to longer interactions.

Students indicated certain courses were better suited for particular modalities. For example, one student believed her math course was more conducive to in-person learning but her language courses were compatible with the online environment due to their inherent discussion elements. A representative statement of this concept was:

I wish that physics was all in person, only because it is difficult to pay attention online sometimes, but I don't think that there's necessarily $100 \%$ of all classes should be in person, or $100 \%$ of all classes should be online. There are certain classes where it almost works better to just have them online.

However, all modalities were perceived by the students to be overwhelming due to a variety of reasons (e.g., social distancing, software issues, difficulty seeing things on camera, poor wifi, etc.).

Generally, students felt the need for more self-accountability and self-teaching in online and hybrid modalities as compared to in-person courses. While online and hybrid allowed for flexibility in scheduling, it was perceived that it was easier to fall behind or procrastinate. The anonymity allowed by online courses was appreciated by some but overall led to decreased participation.

\section{Changes in Learning Strategies}

The second theme centered around students' learning strategies and study habits. The primary issue was the logistical barriers to collaborative study and was noted by all the students. In general, the location of studying changed from common spaces in university buildings to at home. Self-study was the mode of operation for most students using a mixture of class notes, videos, outside resources, and even talking out loud to oneself. A representative statement of this theme was:

Last year we'd meet in the library and we'd [study] or whatever, but this year it's like, we can't even go to the library and do it or we can't all go to someone's room and do it because there's restrictions on how many people can be in a room. We 
can't go to the study room because we're all going to be so far apart. It does make it a lot harder to collaboratively work.

The changes in study habits resulted in a loss of solidarity within the students. The students reported being less prepared for course assessments as they did not understand their ranking with their peers and the understanding of the material. There was also a feeling of loss among the students.

\section{Changes in Relationships with Professors}

The third theme focused on the changing student relationship with their instructors. All nine students expressed a general decline in the quality and quantity of interactions with their professors which became more formal and impersonal. Of those who spoke of establishing a relationship, students reported that a high degree of intentionality was required. The use of video conferencing tools did not aid in understanding as they were considered awkward and did not enable small talk. A representative statement of this theme was:

I would say that some of them [professor relationships] are more formal than others, just given the fact that we haven't really gotten much of a chance to really, I guess, communicate with them [instructors] and have them know us and get to know them. Some of them it's really just... I'll reach out to them about the logistics of the class, homework assignments. That'll really be it. Other ones, it's a little bit closer, just because, again, the culture of the class is closer.

Interestingly, over half of the respondents mentioned their relationship with the teaching assistants were better than that with their professor. When asked which professor they would ask for a letter of recommendation, most did not pick those from the Fall of 2020. The anonymity of the hybrid and online classes were reported as a confounding factor in these relationship challenges.

\section{Discussion}

The authors hypothesized that the perceived distance students had from their peers, their instructors, and their course content during the Fall 2020 semester was affected by the modality (in-person, online, and hybrid) in which their course was offered. The data presented in Table 4 and Figure 3 supported this hypothesis for the student-to-instructor and student-to-student transactional distance.

In the first survey round, mid-way through a semester riddled with mandatory quarantines, reshuffled schedules, and pedagogically misinformed course design, students reported a greater engagement, as represented by a reduced peer and instructor transactional distance, for in-person courses. Figure 3 showed a consistent trend in which the lowest transactional distance, as indicated by positive Likert responses, was for in-person courses, followed by hybrid classes, followed by online classes. This 
indicated that in-person students felt more connected to their instructors and peers than students in online courses. It was hypothesized that hybrid fell between online and inperson classes due to the partial in-person interaction that hybrid facilitated.

The interview data further supported these conclusions as all students interviewed reported fewer interactions in Fall 2020, especially in online courses, when compared to semesters past. Additionally, students indicated the lack of engagement and motivation felt across their curriculum was most perceived in their online and hybrid courses. However, it was noted that some courses were more conducive to an online classroom than others. This was supported by the prior literature that suggested pedagogically informed design of online courses could result in consistent learning outcomes.

Table 4 indicated a reduced modality effect from Round 1 to Round 2 of the survey data. It should be noted that the number of respondents was significantly reduced from Round 1 (159 respondents) to Round 2 (58 respondents). In addition, the distribution across modality in Round 2 was heavily skewed toward hybrid courses. As such, the modality effect analysis for Round 2 should be taken with a sample size filter. Modality analysis done for Round 1, such as Figure 3, was not presented for Round 2.

The data suggested that graduation year and gender were significant factors in student responses, and therein transactional distance. The authors hypothesize that students closer to graduation were less affected by the social impact of COVID-19 learning due to their pre-existing learning community and support networks. Analysis of the gender implications and disaggregating the data to identify if intersecting identities play a role in students' perceived distance is ongoing.

\section{Implications}

The implication of this work extends beyond this institution and engineering courses. The educational environment is still reliant on online courses and reduced in-person interactions. These data must be considered when designing intentional peer-to-peer and student-instructor interactions.

The RSTD data presented herein suggested that students struggled in the online environment, but the authors postulate aspects of the online experience will continue (Shalby, 2021). While not proven in the study, it can be inferred that including course content that reduced the perceived distance, such as group work or non-course related professor and student interactions, could improve the overall learning outcomes of the students. The more students are linked to instructors, the material, and others, the greater the educational outcomes will be.

The authors argue that the increased transactional distance in the online environment, as compared to hybrid and in-person learning, point to the students not fully being immersed in the educational community when learning online. This deficiency is most clear in the student-to-instructor transactional distance. The authors postulate that the decreased in-person connection between students and faculty members was to blame for this perceived increase in distance. Notably, interview 
respondents lamented that their relationships with professors were more forced and contractual than pre-COVID. The authors assert that an intentional effort must be made to re-establish the natural student-instructor relationship that existed before COVID. Instructors must be cognizant to rebuild these relationships to return to the community of learning model.

The most salient theme in the qualitative data was the effect of reduced quality and quantity of student interactions with peers and instructors. Students reported this lack of community to have a net-negative impact on the learning experience. In a separate but related effort, findings from these ancillary themes were used for proposed instructional improvement. For instance, an increased use of group projects, the use of break-out rooms in online learning, and non-course related social engagements were proposed to reduce the distance. Likewise, collaborative spaces for student-to-student learning with social distancing requirements were deployed to improve the perceived distance among peers. The authors argue that these activities and studies are useful to reduce the transactional distance in general, and therefore in a post-COVID environment, these activities will need to be intentionally researched and prescribed.

As higher education emerges into a new 'normal', the authors expect that there are several COVID-induced changes that will become a mainstay. First, the use of an organized course management system is imperative, regardless of course modality. Students have come to expect a well-communicated, central repository of course content including, but not limited to, recorded lectures. The authors postulate that this demand will not go away. Likewise, a sharp uptick in the use of contract cheating platforms, such as Chegg, has been shown through the pandemic and is likely here to stay (Lancaster and Cotarlan, 2021). Students moved rapidly to this mode of support when the student-to-student and student-to-instructor distances increased; however, instructors must be prepared for these 'tools' to remain as the primary avenue for student 'support.' Assessment of learning in any online format must be understood through this lens. As institutions return to normal, the authors hypothesize that students will continue to cheat whenever possible; deliberate organization of the course and redesign of assessment need to be done under this new reality.

There were also implications specific to the institution where this study was performed. The value proposition of this university's education was a residential, community-based learning experience. The data herein showed it was clear that students at this institution come for the "complete educational experience", which includes an immersive educational community and close student-instructor personal relationships. The push to online made this institution no different from the others. It is this community that must be rebuilt and re-established purposely. The data presented herein represented a single snapshot in time but opened many future research questions. The authors assert that HyFlex teaching will not leave higher education even when masks and social distancing are no longer required. As such, future work to measure the impact of the proposed mitigation strategies is ongoing. Additionally, research pertaining to the effective delivery of engineering content to remote learners through 
active, blended, and collaborative delivery is paramount to ensure the highest learning outcomes with HyFlex teaching.

\section{Limitations}

It is worth noting the limitations of the study here. While the surveys were sent out to the entire full-time engineering student population at the college, only approximately one-eighth of the students responded to the survey request. It can be argued that the response rate from students who were already disengaged may have been disproportionately lower than the ones who were more engaged. Therefore, the statistics presented may include self-selection bias towards a lower perceived transactional distance. The same can be said for the qualitative results as interviews were conducted for only the students who volunteered. Furthermore, this study was conducted at one university, a primarily white, private, religious, urban, residential institution. $85 \%$ of incoming students in the fall of 2020 were from the Midwest and $18.4 \%$ of university students were Pell Grant recipients in 2019. As mentioned earlier, the value proposition of this institution may emphasize more on close student-instructor relationship and a sense of community.

\section{Conclusions}

The data presented herein supported the hypothesis that the student experience and transactional distance were affected by the modality in which a course was offered. A dual-round RSTD instrument identified that student-to-instructor and student-to-student transactional distance was affected by modality. The courses with in-person elements had a reduced transactional distance as compared to the exclusively online courses. In addition, students reported an increased lack of engagement and motivational challenges due to the course modality and the external stress of learning during a global pandemic. Qualitative analysis of interview data found that students' learning strategies and experiences were highly correlated to their instructional modality.

Acknowledgements The authors would like to acknowledge Malik Cupid for his assistance on statistical analysis. This material was based upon work supported by NASA under Award No. HEI20 9.0 issued through Wisconsin Space Grant Consortium, and any opinions, findings, and conclusions or recommendations expressed in this material are those of the authors and do not necessarily reflect the views of the National Aeronautics and Space Administration.

\section{References}

Adedoyin, O. B. and Soykan, E. (2020). Covid-19 Pandemic and Online Learning: The Challenges and Opportunities. Interactive Learning Environments, 0(0):1- 13.

Beatty, B. J. (2019). Hybrid-Flexible Course Design. EdTech Books.

Bolliger, D. U. and Halupa, C. (2018). Online Student Perceptions of Engagement, Transactional Distance, and Outcomes. Distance Education, 39(3):299-316. 
Braun, V. and Clarke, V. (2006). Using Thematic Analysis in Psychology. Qualitative Research in Psychology, 3(2):77-101.

Cahapay, M. (2020). A Reconceptualization of Learning Space as Schools Reopen Amid and After Covid-19 Pandemic. Asian Journal of Distance Education, 15(1):269-276.

DePietro, A. (2020). Here's a Look at the Impact of Coronavirus (COVID-19) on Colleges and Universities in the U.S. accessed on 2021-02-19.

Dhawan, S. (2020). Online Learning: A Panacea in the Time of COVID-19 Crisis. Journal of Educational Technology Systems, 49(1):5-22. Publisher: SAGE Publications Inc.

Doo, M. Y., Bonk, C. J., Shin, C. H., and Woo, B.-D. (2020). Structural Relationships Among Self-Regulation, Transactional Distance, and Learning Engagement in a Large University Class Using Flipped Learning. Asia Pacific Journal of Education, 0:1-17.

Fatani, T. H. (2020). Student Satisfaction with Videoconferencing Teaching Quality During the Covid-19 Pandemic. BMC Medical Education, 20(1):396.

Ilagan, J. B. (2020). Overcoming Transactional Distance When Conducting Online Classes on Programming for Business Students: A Covid-19 Experience. In Proceedings of the 28th International Conference on Computers in Education, page 7. Asia-Pacific Society for Computers in Education.

Kalantzis, M. and Cope, B. (2020). After the COVID-19 crisis: Why Higher Education May (and Perhaps Should) Never be the Same. ACCESS: Contemporary Issues in Education, 40(1):51-55.

Kumtepe, A. T., Kumtepe, E. G., and Beylik, A. (2017). Open and Distance Learners' Perceptions of Transactional Distance in Synchronous Online Learning Environments. In Society for Information Technology and Teacher Education International Conference, pages 1679-1684. Association for the Advancement of Computing in Education (AACE).

Lancaster, T. and Cotarlan, C. (2021). Contract Cheating by Stem Students Through a File Sharing Website: A Covid-19 Pandemic Perspective. International Journal for Educational Integrity, 17(1):3.

Li, C. and Lalani, F. (2020). The COVID-19 Pandemic has Changed Education Forever. This is How. accessed on 2021-02-19.

Maloney, E. and Kim, J. (2020). Fall Scenario \#13: A HyFlex Model. [Online; accessed 24. Feb. 2021].

Marsh, H. W. (1992). A Longitudinal Perspective of Students' Evaluations of University Teaching: Ratings of the Same Teachers over a 13-Year Period. Technical report, University of Western Sydney, Macarchur. Presented in 1992 Annual Meeting of the American Educational Research Association.

Milman, N., Irvine, V., Kelly, K., Miller, J., and Saichaie, K. (2020). 7 Things You Should Know About the HyFlex Course Model. [Online; accessed 24. Feb. 2021]. 
Moore, M. (1993). Theory of Transactional Distance. In Keegan, D., editor, Theoretical Principles of Distance Education. Routledge, New York, first edition. Moore, M. G. (2018). The Theory of Transactional Distance. In Moore, M. G. and Diehl, W. C., editors, Handbook of Distance Education, pages 32-46. Routledge, New York, 4 edition.

Moore, M. G. and Kearsley, G. (2011). Distance Education: A Systems View of Online Learning. Cengage Learning, Boston, MA, USA, 3rd edition.

Park, M., Park, J. J., Jackson, K., and Vanhoy, G. (2020). Online Engineering Education Under COVID-19 Pandemic Environment. International Journal of Multidisciplinary Perspectives in Higher Education, 5(1):160-166.

Paul, R. C., Swart, W., Zhang, A. M., and MacLeod, K. R. (2015). Revisiting Zhang's Scale of Transactional Distance: Refinement and Validation Using Structural Equation Modeling. Distance Education, 36(3):364-382.

Pintrich, P. R., Smith, D. A. F., Garcia, T., and McKeachie, W. J. (1991). A Manual for the Use of the Motivated Strategies for Learning Questionnaire (MSLQ). Technical report, National Center for Research to Improve Postsecondary Teaching and Learning, Ann Arbor, MI.

Shalby, C. (2021). Many CSU Students See Big Upsides to Online Learning. Now, There Is a Push to Expand It. Los Angeles Times. Section: California.

Vielma, K. and Brey, E. M. (2020). Using Evaluative Data to Assess Virtual Learning Experiences for Students During COVID-19. Biomedical Engineering Education.

Yilmaz, F. G. K. and Yilmaz, R. (2020). Learning Analytics as a Metacognitive Tool to Influence Learner Transactional Distance and Motivation in Online Learning Environments. Innovations in Education and Teaching International, 0(0):1-11.

Yilmaz, R. and Keser, H. (2017). The Impact of Interactive Environment and Metacognitive Support on Academic Achievement and Transactional Distance in Online Learning. Journal of Educational Computing Research, 55:95-122.

Zhang, A. M. (2003). Transactional Distance in Web-Based College Learning Environments: Toward Measurement and Theory Construction. PhD thesis, Virginia Commonwealth University. 